\title{
Gastrointestinal presentation of COVID-19 in a pediatric heart transplant recipient
}

\author{
Abdelmonem Helal ${ }^{1,2}$, Ahmed F. Elmahrouk ${ }^{3,4^{*}}$ (D), Ahmed A. Jamjoom ${ }^{3}$ and Jameel A. Al-Ata ${ }^{1,5}$
}

\begin{abstract}
Background: Severe acute respiratory syndrome coronavirus 2 (SARS-CoV-2)-associated coronavirus disease 2019 (COVID-19) most commonly causes a mild respiratory illness; however, there are wide ranges of presenting symptoms and disease severity. It has a mortality rate around 7\%.

Case presentation: We present a case of a 9-year-old female patient with hypoplastic left heart syndrome status post heart transplantation at age of 7 days. She presented to our emergency room complaining of intermittent fever, chills, fatigue, poor appetite, and diarrhea.

A throat swab nucleic acid test was positive for severe acute respiratory syndrome coronavirus 2 (SARS-CoV-2). Intravenous fluids therapy was used for correction of hydration status. To the best of our knowledge this is the first reported case of non-pulmonary presentation of coronavirus disease-2019 (COVID-19) in a pediatric heart transplant recipient, which was successfully managed conservatively.

Conclusions: Gastrointestinal manifestations can be the only presenting symptom in pediatric heart transplant recipients with COVID-19. Conservative treatment could be used successfully. Immunomodulatory medications that are used in heart transplant recipients may have protective value in SARS-CoV-2 infection.
\end{abstract}

Keywords: SARS-CoV-2, Pediatric heart transplant recipient, Gastrointestinal presentation

\section{Background}

Severe acute respiratory syndrome coronavirus 2 (SARS-CoV-2)-associated coronavirus disease 2019 (COVID-19) most commonly causes a mild respiratory illness, however, there are wide ranges of presenting symptoms and disease severity [1]. It has a mortality rate around $7 \%[2]$.

Serious and fatal cases of COVID-19 have been recorded in children; however, most pediatric groups tend to have asymptomatic, mild, or moderate presentations. Most of them recover within 1 to 2 weeks of the onset of illness [3].

\footnotetext{
*Correspondence: Ael-Mahrouk@kfshrc.edu.sa; A_marouky@hotmail.com; Ahmed.elmahrouki1@med.tanta.edu.eg

${ }^{3}$ Division of Cardiac Surgery, Cardiovascular Department, King Faisal Specialist Hospital and Research Center, MBC J-16, P.O. Box: 40047, Jeddah 21499, Saudi Arabia

${ }^{4}$ Cardiothoracic Surgery Department, Tanta University, Tanta, Egypt Full list of author information is available at the end of the article
}

\section{Case presentation}

A 9-year-old female patient was presented to our emergency room complaining of intermittent fever, chills, fatigue, poor appetite, and diarrhea. On examination, she was afebrile, (however, her family reported a tympanic temperature of $37.8^{\circ} \mathrm{C}$ at home), oxygen saturation was $99 \%$ on room air, her respiratory rate was 20 breaths per minute with a heart rate of 90 beats/min, and her blood pressure measurement was 100/75 $\mathrm{mmHg}$. The patient's residential area is known to be a hotspot for SARS-CoV2 infection. She had no history of similar manifestations in her family members.

\section{Past medical history}

The child was born with hypoplastic left heart syndrome; she underwent a heart transplant operation at the age of 7 days. She had regular follow-up appointments in our pediatric cardiology clinic. Three years back, she was admitted to our facility with severe 
gastroenteritis attacks that required intensive care unit admission and intravenous inotropic support. After 10 days, she was discharged with stable hemodynamic conditions and normal cardiac functions. Last year, she was complaining about frequent attacks of eczema flare-up, which was treated successfully by a 5-day course of topical hydrocortisone $1 \%$ cream. Her current medications are aspirin $81 \mathrm{mg}$ daily, immunosuppressive therapy in the form of tacrolimus $7 \mathrm{mg}$ once daily, and mycophenolate mofetil $0.3 \mathrm{~g}$ three times a week. The last recorded blood concentration of tacrolimus 1 month before admission was $6 \mathrm{ng} / \mathrm{ml}$, and cardiac allograft function was normal with an elevated baseline creatinine level of $70 \mathrm{umol} / \mathrm{L}$ and cyclic leucopenia with measured white blood cell count of $3.2 \times 10^{9}$ cells $/ 1$ and $5.3 \times 10^{9}$ cells $/ 14$ and 2 months prior to this admission respectively (Fig. 1a). Absolute neutrophilic count was low on admission $\left(0.3 \times 10^{9}\right.$ cells/l) and continue to rise to reach $2.5 \times 10^{9}$ cells/l on follow-up (Fig. 1b).

\section{Differential diagnosis}

The differential diagnosis included bacterial gastroenteritis, viral gastroenteritis, and coronavirus disease-2019 (COVID-19).

\section{Investigations}

Laboratory tests showed a leucopenia (white blood cell count of $2.86 \times 10^{9}$ cells/l) hemoglobin $9.2 \mathrm{~g} / \mathrm{dl}$, creatinine level $120 \mathrm{umol} / \mathrm{l}$, renal Co2 $12 \mathrm{mmol} / \mathrm{l}$, procalcitonin level $8.4 \mathrm{ng} / \mathrm{mL}$ (normal range up to $2 \mathrm{ng} / \mathrm{mL}$ ), D dimer 1.555 $\mathrm{mg} / \mathrm{l}$ (normal range up to $0.555 \mathrm{mg} / \mathrm{L}$ ), ferritin $229 \mu \mathrm{g} / \mathrm{l}$,

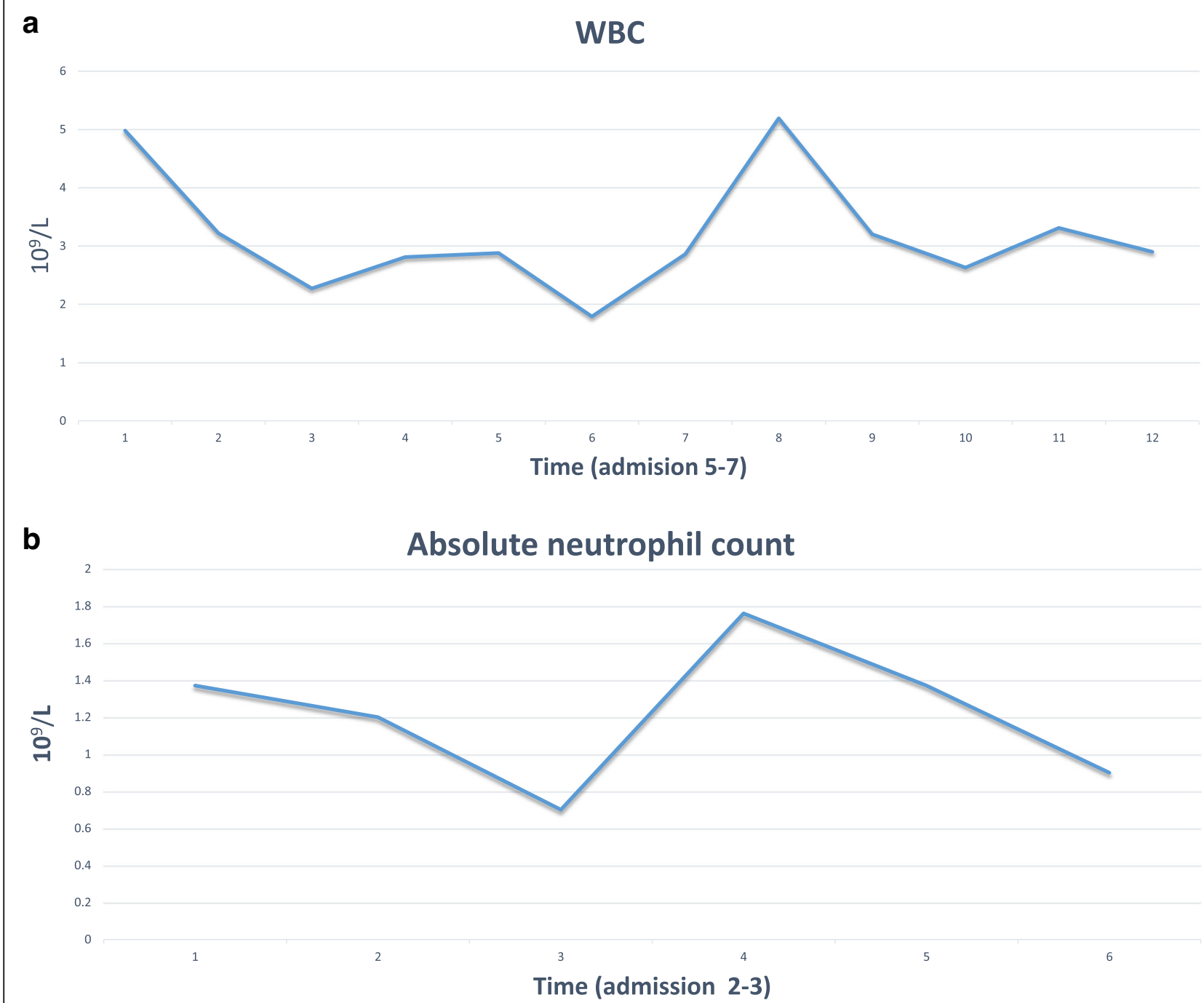

Fig. 1 a A flow chart for leucocytic count (WBC) showing cyclic leucopenia prior COVID-19 infection, and a leucocytic count lower than her usual baseline during this admission, which started to recover by discharge. b A flow chart for absolute neutrophilic count showing neutropenia during COVID-19 infection, which started to recover by discharge 


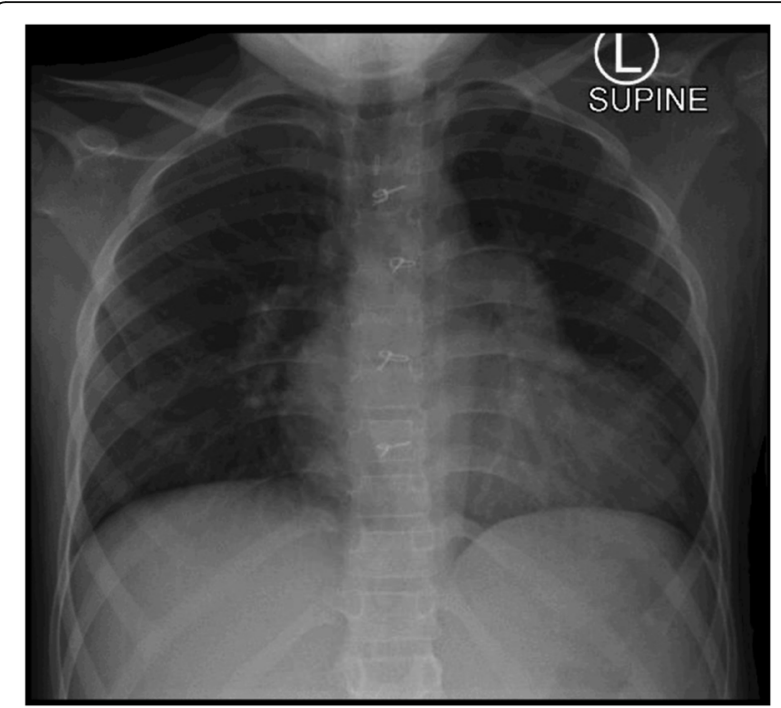

Fig. 2 Chest X-ray showing that the cardiac silhouette is enlarged with the prominence of the left pulmonary artery. The lung fields and the costophrenic angles are clear

and ProBNP $680 \mathrm{pg} / \mathrm{ml}$ (normal range up to $450 \mathrm{pg} / \mathrm{ml}$ ). Chest X-ray showed clear both lung fields and costophrenic angles. (Fig. 2).

A throat swab nucleic acid test was positive for SARSCoV-2. Vancomycin-resistant enterococci swab and methicillin-resistant Staphylococcus aureus swab screening were negative. Blood, urine, and stool cultures were negative for bacterial infection, and rapid antigen stool test was negative. Echocardiography study showed normal systolic and diastolic function with no pericardial effusion (Fig. 3).

\section{Management}

Immunosuppressive drugs were adjusted in the form of tacrolimus $5 \mathrm{mg}$ as tacrolimus trough level concentration on admission was $11 \mathrm{ng} / \mathrm{ml}$ (Fig. 4) and continued on the same dose of mycophenolate mofetil and aspirin. Since the child condition was stable, a decision was made in a multi-disciplinary meeting between pediatric cardiology, cardiac surgery, pediatric infectious disease, and immunology to proceed with conservative management, and we did not start any antiviral medications for SARS-CoV-2 virus infection. Intravenous fluids therapy was used for the correction of hydration status. Body temperature was normal during the admission period (Fig. 5), gastrointestinal symptoms were gradually improving over three days, and she resumed her normal oral intake. On the 7th day of admission, laboratory tests showed creatinine level 70 umol/l, renal Co2 $19 \mathrm{mmol} / \mathrm{l}$. The patient was discharged after two consecutive negative reverse transcriptasepolymerase chain reaction throat swabs for SARS-CoV-2 on the 12th and 18th days from admission.

\section{Follow-up}

The patient remained hospitalized for 15 days of isolation as per the ministry of health guidelines. She was scheduled for a follow-up appointment in the pediatric cardiology clinic.

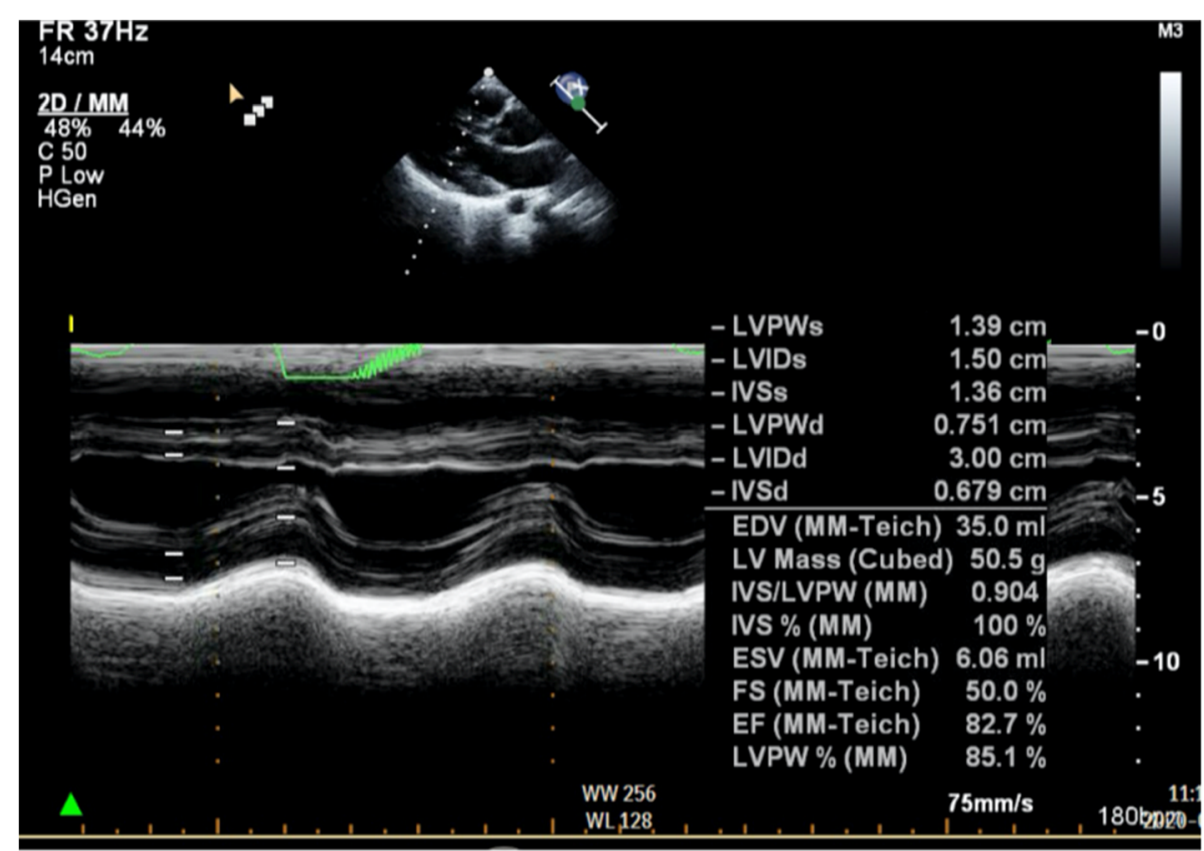

Fig. 3 Echocardiography study showed normal systolic and diastolic function with no pericardial effusion 


\section{FK506 (Tacrolimus)}

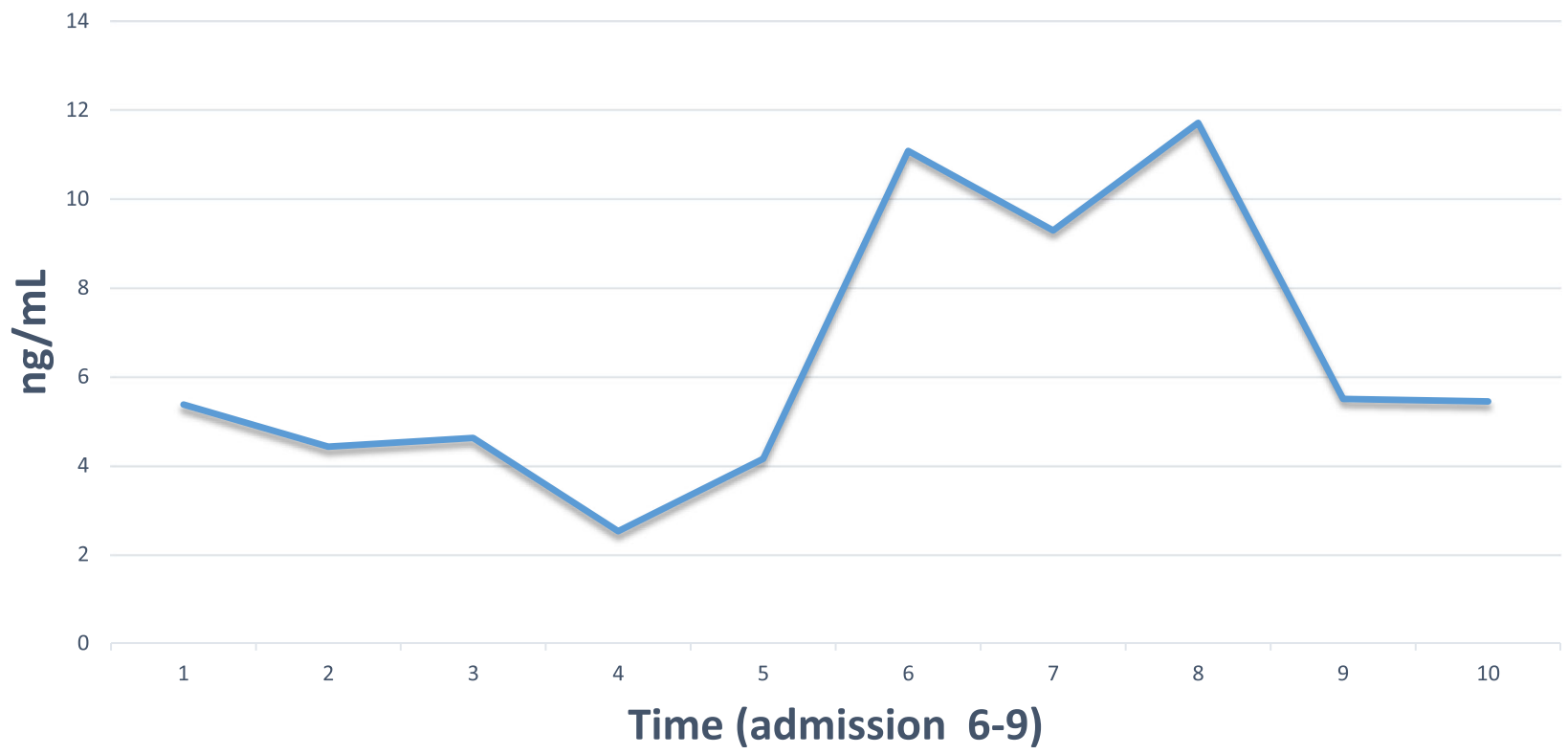

Fig. 4 A flow chart of tacrolimus trough level showing an elevated level during the initial presentation of the disease, and the decrease of the level in response to dose adjustment

\section{Discussion}

Multiple reports suggested that pediatric COVID-19 patients experience not only less severe but different symptoms than adults. Their rate of hospitalization was $5.7 \%$ with less than $0.6 \%$ needed ICU admission, with mortality rate of $0.11 \%$ [4].

The severity of COVID-19 tends to be caused not only by viral invasion and proliferation but also by an extreme immune response characterized by cytokine storm, myocardial injury, and coagulopathy [5]. Questions were raised about whether heart transplant recipients may be at elevated risk of adverse outcomes with SARS-CoV-2 infection due to several specific comorbidities following cardiac transplantation, including hypertension and cardiac allograft vasculopathy [6]. In addition, while maintaining immunosuppression predisposes recipients to a higher risk of infection, immunosuppression has also been theorized as being protective against cytokine storms [7]. Moreover, an earlier study demonstrated that FK506 (Tacrolimus) inhibited the growth and replication of

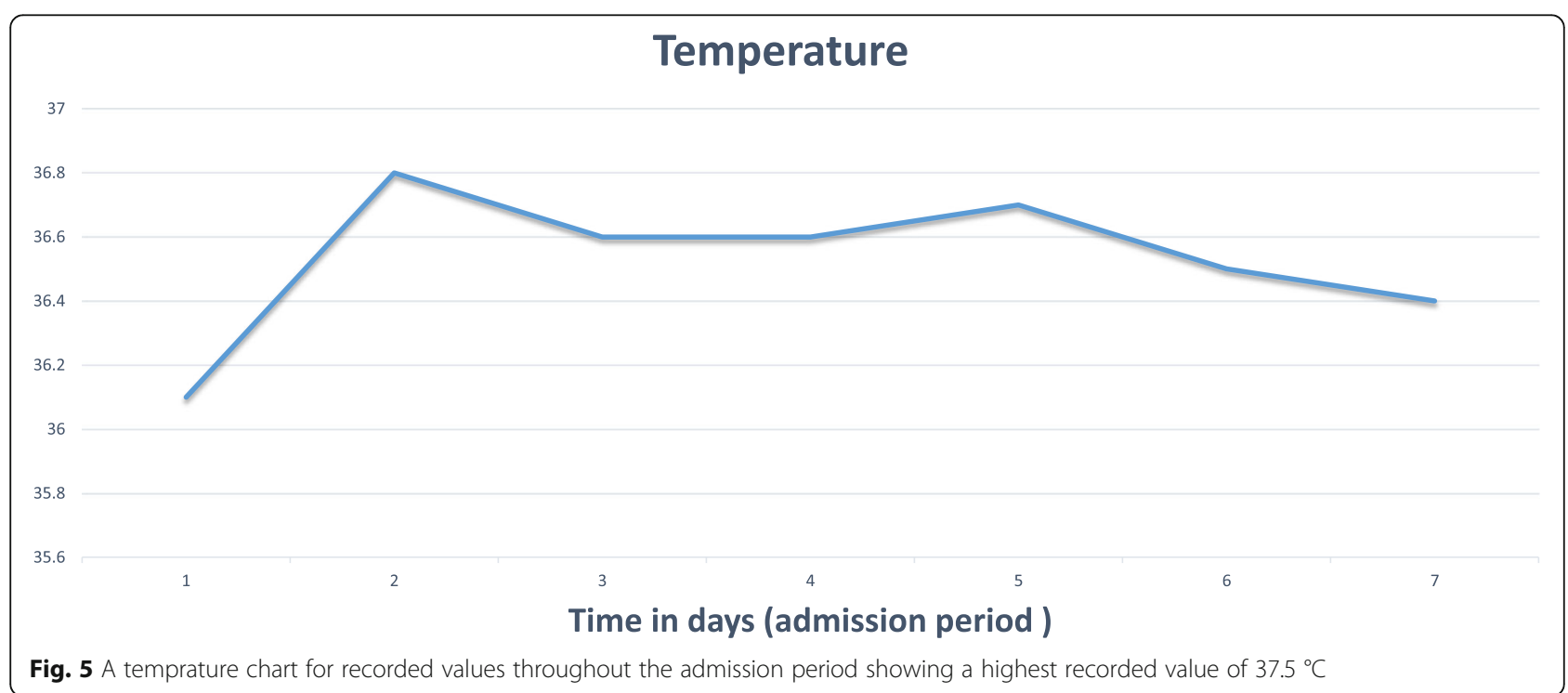

Fig. 5 A temprature chart for recorded values throughout the admission period showing a highest recorded value of $37.5^{\circ} \mathrm{C}$ 
human coronaviruses SARS-CoV, at low, non-cytotoxic concentrations in cell culture [8]. Our patient was receiving tacrolimus at the time of infection; therefore, she may have a more efficient immune response than if she had received corticosteroid.

There have been conflicting reports about mortality among recipients of a heart transplant with COVID-19. While one report did not find any increase in mortality [1], another article showed $25 \%$ mortality in an adult cohort of 22 transplant recipients with SARS-CoV-2 infection [9].

In the case report by Russell MR et al. [10], the patient was admitted to receive intravenous immunoglobulin 1 week after surveillance laboratory studies showed antihuman leukocyte antigen antibody. Because of the history of cough, SARS-CoV-2 reverse transcriptase polymerase chain reaction test was performed and returned positive. They suggested that careful measurement of donorspecific antibodies be undertaken in heart transplant survivors of COVID-19 [10].

Our child had a good immunosuppressive balance, with no signs of rejection. Moreover, echocardiography study showed normal systolic and diastolic function with no pericardial effusion. For that, we did not feel the need to perform donor specific antibodies test.

Our patient had an acceptable course over the last 9 years. Although laboratory investigation showed increased levels of inflammatory markers, the clinical presentation was in a mild form with no significant signs of systemic viral manifestations or cytokine storm. With all previous factors, we decided not to start antiviral medication. Monitoring hemodynamic parameters and correction of hydration status were the main line of management. The patient improved slowly on this conservative treatment.

\section{Conclusions}

Gastrointestinal manifestations can be the only presenting symptom in pediatric heart transplant recipients with COVID-19. Conservative treatment could be used successfully. Immunomodulatory medications that are used in heart transplant recipients may have protective value in SARS-CoV-2 infection. More studies are needed to evaluate the difference in clinical course and outcome between pediatric and adult heart transplant recipients with COVID-19.

\section{Abbreviations}

SARS-CoV-2: Severe acute respiratory syndrome coronavirus 2; COVID-19: Coronavirus disease-2019

\section{Authors' contributions}

AH have conducted a literature search; data acquisition; data interpretation and drafted the manuscript, AE have also conducted a literature review; data acquisition; data interpretation; data analysis and drafted the manuscript, AJ have made a substantial contribution to the conception, the acquisition and the interpretation of data; he also substantively revised the manuscript. JA have conducted a literature review; analysis and interpretation of data; he also critically revised the manuscript. All authors have read and approved the final manuscript.

\section{Funding}

This research received no specific grant from any funding agency in the public, commercial, or not-for-profit sectors.

\section{Availability of data and materials}

Data are available with the corresponding author upon request.

\section{Ethics approval and consent to participate}

The authors declare that they have no competing interests. The case report was approved by the institutional review board (IRB) of King Faisal specialist hospital and research center, Jeddah, Saudi Arabia, under approval number: IRB 2020-CR-10.

\section{Consent for publication}

A written consent for retention and use of unidentified data was obtained from the patient guardian.

\section{Competing interests \\ None}

\section{Author details}

'Pediatric Cardiology Section, Department of Pediatrics, King Faisal Specialist Hospital \& Research Center, Jeddah, Kingdom of Saudi Arabia. ${ }^{2}$ Department of Pediatrics and Pediatric Cardiology, Cairo University, Cairo, Egypt. ${ }^{3}$ Division of Cardiac Surgery, Cardiovascular Department, King Faisal Specialist Hospital and Research Center, MBC J-16, P.O. Box: 40047, Jeddah 21499, Saudi Arabia. ${ }^{4}$ Cardiothoracic Surgery Department, Tanta University, Tanta, Egypt. ${ }^{5}$ Section of Pediatric Cardiology, Department of Pediatrics, King Abdulaziz University, Jeddah, Saudi Arabia.

Received: 10 September 2020 Accepted: 15 October 2020

Published online: 09 November 2020

\section{References}

1. Li F, Cai J, Dong N (2020) First cases of COVID-19 in heart transplantation from China. J Heart Lung Transplant 39(5):496-497. https://doi.org/10.1016/j.healun. 2020.03.006 Epub 2020 Mar 17. PMID: 32362394: PMCID: PMC7156127

2. Dong E, Du H, Gardner L. An interactive web-based dashboard to track COVID19 in real time. Lancet Infect Dis. 2020; 20(5): 533-534. doi: https://doi.org/10. 1016/S1473-3099(20)30120-1. Epub 2020 Feb 19. Erratum in: Lancet Infect Dis. 2020 Sep;20(9):e215. PMID: 32087114; PMCID: PMC7159018.

3. Chang TH, Wu JL, Chang LY (2020) Clinical characteristics and diagnostic challenges of pediatric COVID-19: A systematic review and meta-analysis. J Formos Med Assoc 119(5):982-989. https://doi.org/10.1016/j.jfma.2020.04. 007 Epub 2020 Apr 16. PMID: 32307322; PMCID: PMC7161491

4. CDC COVID-19 Response Team (2020) Coronavirus Disease 2019 in Children - United States, February 12-April 2, 2020. MMWR Morb Mortal Wkly Rep 69(14):422-426. https://doi.org/10.15585/mmwr.mm6914e4 PMID: 32271728; PMCID: PMC7147903

5. Guzik TJ, Mohiddin SA, Dimarco A, Patel V, Savvatis K, Marelli-Berg FM, Madhur MS, Tomaszewski M, Maffia P, D'Acquisto F, Nicklin SA, Marian AJ, Nosalski R, Murray EC, Guzik B, Berry C, Touyz RM, Kreutz R, Wang DW, Bhella D, Sagliocco O, Crea F, Thomson EC, McInnes IB (2020) COVID-19 and the cardiovascular system: implications for risk assessment, diagnosis, and treatment options. Cardiovasc Res 116(10):1666-1687. https://doi.org/10. 1093/cvr/cvaa106 PMID: 32352535; PMCID: PMC7197627

6. Ketcham SW, Adie SK, Malliett A, Abdul-Aziz AA, Bitar A, Grafton G, Konerman MC (2020) Coronavirus Disease-2019 in Heart Transplant Recipients in Southeastern Michigan: A Case Series. J Card Fail 26(6):457-461. https://doi.org/10.1016/j. cardfail.2020.05.008 Epub 2020 May 14. PMID: 32417380; PMCID: PMC7224667 
7. Alijotas-Reig J, Esteve-Valverde E, Belizna C, Selva-O'Callaghan A, Pardos-Gea J, Quintana A, Mekinian A, Anunciacion-Llunell A, Miró-Mur F (2020) Immunomodulatory therapy for the management of severe COVID-19. Beyond the anti-viral therapy: A comprehensive review. Autoimmun Rev 19(7):102569. https://doi.org/10.1016/j.autrev.2020.102569 Epub 2020 May 3. PMID: 32376394; PMCID: PMC7252146

8. Carbajo-Lozoya J, Müller MA, Kallies S, Thiel V, Drosten C, von Brunn A (2012) Replication of human coronaviruses SARS-CoV, HCoV-NL63 and HCoV-229E is inhibited by the drug FK506. Virus Res 165(1):112-117. https:// doi.org/10.1016/j.virusres.2012.02.002 Epub 2012 Feb 10. PMID: 22349148; PMCID: PMC7114512

9. Latif F, Farr MA, Clerkin K, Habal MV, Takeda K, Naka Y, Restaino S, Sayer G, Uriel N (2020) Characteristics and Outcomes of Recipients of Heart Transplant With Coronavirus Disease 2019. JAMA Cardiol:e202159. https:// doi.org/10.1001/jamacardio.2020.2159 Epub ahead of print. PMID: 32402056; PMCID: PMC7221850

10. Russell MR, Halnon NJ, Alejos JC, Salem MM, Reardon LC (2020) COVID-19 in a pediatric heart transplant recipient: Emergence of donor-specific antibodies. J Heart Lung Transplant 39(7):732-733. https://doi.org/10.1016/j. healun.2020.04.021 Epub 2020 Apr 29. PMID: 32430156; PMCID: PMC7189188

\section{Publisher's Note}

Springer Nature remains neutral with regard to jurisdictional claims in published maps and institutional affiliations.

\section{Submit your manuscript to a SpringerOpen ${ }^{\circ}$ journal and benefit from:}

- Convenient online submission

- Rigorous peer review

- Open access: articles freely available online

High visibility within the field

- Retaining the copyright to your article

Submit your next manuscript at $\boldsymbol{\nabla}$ springeropen.com 